\title{
EL DERECHO INDÍGENA SUBORDINADO Y LA CONSULTA CONTRA LOS PUEBLOS: UN CASO MEXICANO ${ }^{1}$
}

Magdalena Gómez

Abogada, especialista en derecho indígena, académica de la Universidad Pedagógica Nacional y articulista del

Periódico La Jornada en México

México

\section{Resumen}

Mostraré elementos que dan cuenta de la relación desigual del derecho indígena vigente en México frente a las reformas neoliberales en materia energética y su contraste de despojo a los territorios de los pueblos indígenas., analizando la ventana de oportunidad que abrió la incorporación de los tratados internacionales al orden interno. El derecho a la consulta será la puerta de entrada. Nos detenemos en la consulta al pueblo zapoteco de Juchitán, Oaxaca, México. Se identificará la defensa jurídica y política de ese pueblo indígena y los mecanismos oficiales para lograr legitimación política y eventualmente aval legal al cumplimiento de dicho derecho.

1 Una primera versión se presentò en el IX Congreso de RELAJU- 2015, "Sociedades Plurales y Estados Nacionales:Límites y desafíos para la efectividad de los derechos”,Pirenópolis, Goias, Brasil,29 de septiembre-2 de octubre de 2015 


\begin{abstract}
My proposal is to show the elements that prove the unequal relation of current indigenous Law in Mexico, against the neoliberal reforms in energetic matters and in general and its contrast dispossession to the indigenous peoples territories, analyzing the opportunity that the incorporation of the International treaties opened to the internal order. The consultant right would be the opening for that way. We stand on the consultant right for the zapotec Peoples of juchitan, Oaxaca, México. It will be identified the legal and politic defense from that indigenous people and official opinions will be identified to get polític legitimacy and eventually legal support for the compliment of this right.
\end{abstract}

Palabras clave: Pueblos indígenas, territorio, consulta, representación, Estado-empresas. 


\section{INTRODUCCIÒN}

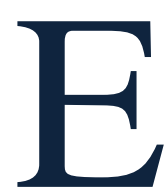

ste artículo se ubica en la etapa actual,la de la justiciabilidad, donde los pueblos indígenas en la región están defendiendo sus territorios ,utilizando los derechos que lograron las últimas tres décadas y cuyo proceso en su momento analicè como el de juridicidad. El componente central de la resistencia indígena es la organización, y el uso del derecho tiene sentido sólo en ese contexto. (Gómez:2011). Si bien se aborda desde el caso mexicano, encontramos que en América latina se viven problemáticas similares, pues lo son en la región los caminos del neoliberalismo.

El marco jurídico indígena, precario a nivel nacional, (Gómez:2005), se amplió a raíz de la reforma constitucional en materia de derechos humanos, que dio entrada plena a tratados internacionales, como el convenio 169 de la OIT, entre otros, colocados en el mismo nivel que la Constitución. (Ferrer Mc Gregor et.al:2013).

Sin embargo, un primer escenario y muy preocupante, es el relativo a las implicaciones de la decisión de la Suprema Corte de Justicia de la Nación en torno a la interpretación de los alcances del artículo primero constitucional en materia de derechos humanos.El Pleno determinó que los derechos humanos reconocidos en tratados internacionales están al mismo nivel de la Constitución, ello de entrada se ha ponderado como muy positivo al establecer el bloque de constitucionalidad y precisar que la Constitución y los tratados internacionales "no se relacionan jerárquicamente" y sin embargo acto seguido se agregó : "Entendiendo que cuando en la Constitución Federal existe una restricción expresa al ejercicio de los derechos fundamentales, se deberá estar a lo que indica la norma constitucional". (Contradicción 293/2011).¿cual es el impacto en materia indígena cuando el artículo segundo constitucional fue redactado pleno de restricciones y candado frente a lo que señala el convenio 169 de la OIT? Para no hablar de la Declaración de la ONU, que tiene otro status jurídico aún cuando hace parte del derecho internacional de derechos humanos y México votó a favor de su aprobación.(Cossío:2013)

Van tres ejemplos. En materia de consulta la fr. IX del art. $2^{\circ}$ la relacionó al Plan Nacional de Desarrollo, mutilando la dimensión integral de la consulta que se establece en el convenio 169, con anterioridad la Corte había establecido que en el art. $2^{\circ}$ se incluían mínimos pero ahora con ese criterio $¿$ cual norma prevalece ante la restricción constitucional expresa, la consulta es para algo tan específico como el 
PND? (Gómez:2004 y 2005).Otra implicación grave, la fr. VI del art. $2^{\circ}$ limita expresamente el acceso al uso y disfrute preferente de los recursos naturales de los lugares que habitan y ocupan, bajo el respeto a las formas y modalidades de propiedad y tenencia de la tierra establecidas en la constitución y a las leyes de la materia, todas estas restricciones ¿prevalecerán sobre el convenio 169 que regula la trascendencia del acceso al territorio para la supervivencia de los pueblos? (Gómez:2014).

Un tercer ejemplo es el relativo a la autonomía para aplicar sus propios sistemas normativos en la regulación de sus conflictos internos y que la ley establecerá los casos y procedimientos de validación por los jueces o tribunales correspondientes.(fr.II art. $2^{\circ}$ ) En esta fracción en realidad no se reconocen los sistemas normativos sino que remite su validación a la ley, que por cierto no existe, y al poder judicial. Todo ello contraría lo señalado en el convenio 169.Por otra parte la Corte admitió la vinculatoriedad de la jurisprudencia de la Corte Interamericana la cual en materia indígena es avanzada y está alineada a tratados internacionales, $\mathrm{y}$ justamente se refieren a los temas donde el artículo segundo tiene restricción ¿Cuál prevalece en congruencia con el criterio regresivo acordado? .

\section{EXTRACTIVISMO CONTRA EL DERECHO DE LOS PUEBLOS INDÍGENAS}

La actual amenaza extractivista tiene alcances de fondo. El Congreso de la Unión a iniciativa del Ejecutivo aprobó en 2013,reformas constitucionales en materia energética y leyes que las reglamentan, afectando seriamente el sentido de los artículos constitucionales 25,27 y 28 para promover la privatización del subsuelo mexicano y nulificando en los hechos los derechos de los pueblos, en especial su derecho al territorio. Se modificaron decisiones políticas fundamentales, que dieron sentido al pacto histórico de 1917, con la finalidad de otorgar a particulares contratos de utilidad compartida y privatizar la refinación del petróleo, la petroquímica, el gas, la industria eléctrica y la distribución y comercialización de los energéticos, Ahora es retórico el principio de que corresponde a la nación el dominio directo de todos los recursos naturales.

Entre otras condiciones, establece la posibilidad de expropiar la tierra cuyos propietarios se nieguen a llegar a un acuerdo para rentarla o venderla; en este caso el concepto de utilidad pública se convierte en los hechos en utilidad privada. El acuerdo que las partes hayan alcanzado, será validado ante tribunales agrarios o jueces de distrito, teniendo el carácter de sentencia. 
Señalan que el contrato será nulo cuando se incurra en prácticas abusivas $\mathrm{y}$ discriminatorias $o$ se busque influir indebidamente en la decisión de las personas involucradas. Señala que podrán emplearse las figuras jurídicas de arrendamiento, servidumbre voluntaria, ocupación superficial, compraventa o cualquier otra que no contravenga la ley. Se cubren con la definición de las opciones de contraprestación: un dinerito al que denominan pagos en efectivo. También se habla de pagos en especie como los clásicos proyectos comunitarios, todo por unas canchas, un centro de salud sin médicos ni equipo ni medicinas, y no podía faltar la opción humillante: pueden pasar de propietarios a empleados, ellos, su familia o toda la comunidad (artículo 101, fracción quinta). Y cierran su pinza protectora al capital trasnacional en el proyecto de la ley de órganos reguladores coordinados en materia energética, artículo 33, según el cual los contratos para exploración y extracción de hidrocarburos, para tender ductos, tendido de infraestructura eléctrica y otras construcciones relacionadas, se otorgarán conjuntamente con la respectiva declaración de utilidad pública de los predios en cuestión. Ni hablar de las concesiones mineras, que se consideran casi pase automático a los hidrocarburos. En ese contexto, poco importa que, en lugar de expropiación cuando los titulares de las tierras se opongan al despojo, para llamar a las cosas por su nombre, el Congreso de la Unión refiera a la llamada ocupación temporal como supuesto paliativo. El capital financiero trasnacional tiene así certidumbre para sus inversiones en áreas consideradas estratégicas.

Todavía en 1983 el Comité de Derechos Humanos de la ONU, destacó que era la primera vez que en un informe (de México) se insistía en el dominio de los recursos naturales como elemento del derecho de los pueblos a disponer de ellos mismos y que la experiencia mexicana ,demostraba que cuanto más dueño de su economía era un país mejor podía luchar contra la intervención extranjera, preservar culturas nacionales y defender los derechos humanos, y se expresó el deseo de saber qué influencia podrían tener esas mediciones económicas sobre el disfrute de los derechos humanos en México (parágrafo 63. CCPR/C/SR.386, 387 y 404). La disyuntiva planteada no era nueva. Nuestra historia da cuenta de la misma. Para no ir tan lejos, en 1908 se debatió un artículo, el 144, del proyecto de Ley Minera en el cual se consignaba la cancelación de la adquisición de propiedades mineras a las sociedades que no fueran organizadas conforme a las leyes mexicanas. A consecuencia de la presión ejercida por la Cámara Minera de México, entre otros 
grupos económicos, el gobierno de Porfirio Díaz eliminó el artículo referido.

Este contexto motivó el sentido de dominio establecido en favor de la nación en el artículo 27 constitucional de 1917, que hoy, de forma retórica, se menciona en la ley de hidrocarburos, para sustentar la prohibición, so pena de nulidad, de que las trasnacionales acuerden con los dueños de las tierras involucradas la contraprestación asociada a la producción de hidrocarburos. En síntesis, el Estado deja de representar a la nación para garantizar las mejores condiciones al capital trasnacional.

Tampoco es que en la lógica de seguridad nacional el Estado se confíe; por ello, desde su Pacto por México ${ }^{2}$ incluyó el complemento de sus reformas llamadas estructurales y no es otro que el de la criminalización. A partir del mismo, se preparan para reglamentar el artículo 29 constitucional y expedir una nueva ley que permita normar los términos y condiciones de la suspensión de garantías (Compromiso 23). Además, acordaron en el mismo pacto impulsar la ley federal sobre el uso legítimo de la fuerza pública al indicar que como sucede en otros países, se creará una ley que establezca parámetros claros para el uso de la fuerza pública (Compromiso 28).

2 Es el documento político que promovió el Presidente de la República Enrique Peña Nieto, en 2013, con la agenda neoliberal de compromisos de
Así tenemos, la consolidación de la vía jurídica para consumar el despojo de tierras, lo cual plantea desafíos a la centenaria resistencia indígena y al alcance real de sus derechos hasta hoy reconocidos. (Gómez:2015)

\section{EL ENTRAMADO DEL DERECHO A LA CONSULTA}

Podemos observar que la apelación a la violación del derecho a la consulta, se està utilizando por los pueblos indígenas en la región, como un mecanismo que busca impedir la consolidación de proyectos que afectan su derecho al territorio. Este fenómeno se convierte en una vìa indirecta , en general frágil jurídicamente, pero en ocasiones efectiva como mecanismo de movilización política.

Acerca del derecho a la consulta, establecido en el artículo 6 del Convenio 169 de la Organización Internacional del Trabajo (OIT) existe jurisprudencia muy diversa y criterios expresados desde los órganos de control de la OIT a través de su comité de expertos así como del sistema interamericano ( OIT:2009 a) y b). Se ha insistido en la lógica de que la consulta se oriente a la construcción de acuerdos, lo cual plantea de parte de los estados serias

reformas entre ellas la educativa y la energética y al que se sumaron las fuerzas políticas partidistas de todas las tendencias. 
objeciones. Una de ellas, la más álgida, es la relativa a la situación que se genera cuando la consulta no concluye con un acuerdo, con el consentimiento de un pueblo para que el Estado de manera directa, o a través de una concesión, realice un determinado proyecto, defina una política pública o bien se emita determinada legislación. En ese caso se dice de parte estatal que la consulta no entraña un derecho de veto. Y aquí nos colocamos en un tema que será necesario abordar en todas sus implicaciones, es el relativo al vínculo de la consulta con el derecho de propiedad.

Es importante aclarar que este derecho sería el equivalente del derecho al debido proceso, los pueblos alegan la violación al derecho a la consulta cuando se vulnera su derecho a sus tierras y territorios. El territorio es un concepto más amplio que la mera tenencia de la tierra, ¿qué implicación concreta tiene que dos instrumentos internacionales, como son el Convenio 169 de la OIT y la referida declaración de la ONU, reconozcan ese

\footnotetext{
${ }^{3}$ La comunidad Awas Tingni es una comunidad indígena situada en la Costa Atlántica de Nicaragua. En los años 90 el Gobierno nicaragüense concedió a la compañía surcoreana SOLCARSA derechos de explotación maderera sobre los territorios ancestrales de la comunidad, a pesar del reconocimiento por parte de la Constitución de Nicaragua y de otras leyes posteriores del derecho de los pueblos indígenas al disfrute de sus tierras tradicionales. La comunidad acudió sin éxito a instancias judiciales tanto locales como nacionales para revocar dicha concesión. Por ello, decidió acudir al sistema de protección de los derechos humanos instaurado por la Organización de Estados
}

derecho?. En este sentido el derecho a la consulta, sin la implicación del derecho al consentimiento previo, que consigna la Declaración de Naciones Unidas sobre Derechos de los Pueblos Indígenas, afecta de entrada a la naturaleza de su derecho de propiedad (Gómez:2006). Es distinto que se haga una propuesta de un proyecto a quien tiene un derecho reconocido, en este caso los pueblos indígenas y ellos decidan si la aceptan o no. No se trata de un derecho de veto, es un derecho a secas, ni más ni menos. Vetar significaría detener una decisión ya tomada por alguien distinto a quien tiene la titularidad del derecho, así sea el Estado o la trasnacional que obtuvo una concesión. ¿Nos vamos a encontrar, en clave indígena,que estamos ante derechos de propiedad que lo son solo retóricos?

\section{La Corte Interamericana de}

Derechos Humanos marcó un parteaguas a través de la sentencia en el caso Awas Tingni $^{3}$, donde si bien señaló que se otorgó una concesión sin consulta, ante todo abonó en la reflexión fundamental sobre el

Americanos (OEA). Tras un largo y complicado proceso, la Corte Interamericana de Derechos Humanos, con sede en San José de Costa Rica, emitió el 31 de agosto de 2001 una decisión histórica. La Corte Interamericana sostuvo que el Estado nicaragüense había violado los derechos de propiedad de la comunidad Awas Tingni sobre sus tierras tradicionales. En consecuencia, la Corte ordenó a Nicaragua que demarcara y titulara las tierras tradicionales de la comunidad, que cesara en cualquier actividad que pudiera poner en peligro dichos derechos, y que estableciera un mecanismo adecuado para asegurar los territorios de todas las comunidades indígenas del país. 
derecho de propiedad de las comunidades indígenas. En este sentido arroja luces el importante estudio de la Comisión Interamericana de Derechos Humanos sobre tierras ancestrales y recursos naturales (CIDH:2010) Detengámonos en este punto, en sus tesis centrales:

- Los pueblos indígenas y tribales tienen formas de vida únicas, y su cosmovisión se basa en su estrecha relación con la tierra. Las tierras tradicionalmente utilizadas y ocupadas por ellos son un factor primordial de su vitalidad física, cultural y espiritual.

"para las comunidades indígenas la relación con la tierra no es meramente una cuestión de posesión y producción sino un elemento material y espiritual del que deben gozar plenamente, inclusive para preservar su legado cultural y transmitirlo a las generaciones futuras".

Los territorios ancestrales tienen un profundo valor espiritual para los pueblos indígenas y tribales. Además, los pueblos indígenas y tribales consideran que ciertos lugares, fenómenos o recursos naturales son especialmente sagrados de conformidad con su tradición, y requieren especial

\footnotetext{
4 ... En el plano internacional, se puede observar la aplicación de los estándares que garantizan el derecho de consulta, por parte de tribunales, entre otros, de los siguientes países: i. Argentina, Sala Primera de la Suprema Corte de Justicia de Mendoza, Expediente ciento dos punto seiscientos treinta y uno (102.631), sentencia de dieciocho de
}

protección. Los territorios y recursos naturales de los pueblos indígenas y tribales son un elemento constitutivo de su cosmovisión y su religiosidad, dado que para ellos, los conceptos de familia y de religión se conectan íntimamente con los lugares donde los cementerios ancestrales, los lugares de significado e importancia religiosos y los patrones de parentesco se han desarrollado a partir de la ocupación y uso de sus territorios físicos.

Como observamos, la CIDH plantea fuertes desafíos a la normatividad mexicana y ofrece criterios de interpretación que habrá que hacer valer en el contexto del artículo primero constitucional reformado en 2011.

\section{EL NUEVO MODELO O LA CONSULTA POR OTROS MEDIOS: MANIPULACIÓN DEL DISCURSO JURÍDICO : EL CASO DE JUCHITÁN}

Con el antecedente de movimientos significativos, como el yaqui y el de Cherán, que lograron obtener de la Suprema Corte de Justicia (SCJN) resoluciones favorables, si bien insuficientes frente a la violación del derecho a la consulta ${ }^{4}$

mayo de dos mil doce, en la que se indicó: “... el derecho a la consulta previa de los pueblos indígenas... es, "en esencia, de un derecho fundamental de carácter colectivo,..”; ii. Bolivia, Tribunal Constitucional de Bolivia, Expediente dos mil ocho guión diecisiete mil quinientos cuarenta y siete guion treinta y seis guion RAC (2008-17547- 
(Gómez:2014), el Estado mexicano ha diseñado una estrategia que combina la cooptación con el discurso jurídico ,para sustentar un mensaje equívoco de supuesto respeto al derecho a la consulta. Un soporte para que ello sea posible es la división comunitaria y la consecuente pérdida de las instancias representativas de los pueblos indígenas.

El 30 de julio de 2015 culminó el proceso de consulta en la comunidad zapoteca de Juchitán de Zaragoza, Oaxaca, México, respecto a la propuesta de la Empresa Eólica del Sur. Fue coordinado por la Secretaría de Energía (SENER) con alianza y o aval de otras dependencias federales, instituciones académicas y gobierno del estado de Oaxaca. Previamente en 2013 la Comisión Nacional para el Desarrollo de los Pueblos Indígenas (CDI) emitió el Protocolo para la

36-RAC), sentencia de veinticinco de octubre de dos mil diez, en la que se señala:"... La consulta, de acuerdo al art. 15.2 del Convenio No 169 de la OIT se extiende a los recursos existentes en las tierras de los pueblos indígenas ..”; iii. Colombia, la Corte Constitucional de Colombia en sentencia SU guión cero treinta y nueve diagonal noventa y siete (SU039/97), de tres de febrero de mil novecientos noventa y siete, estimo: “... que la institución de la consulta a las comunidades indígenas que puedan resultar afectadas con motivo de la explotación de los recursos naturales, comporta la adopción de las relaciones de comunicación y entendimiento, signadas por el mutuo respeto y la buena fe entre aquellas y las autoridades públicas. (...) No tiene por consiguiente el valor de consulta la información o notificación que se hace a la comunidad indígena sobre un proyecto de exploración o explotación de recursos naturales...". El resaltado no está en original. En este caso la Corte Constitucional de Colombia otorgo el amparo y, como consecuencia, implementación de consultas a pueblos y comunidades indígenas señalando su conformidad con estándares del Convenio 169 de la Organización Internacional del Trabajo sobre Pueblos Indígenas y Tribales en Países Independientes ${ }^{5}$ que sirvió de base para la elaboración de uno específico para Juchitán denominado "Protocolo para la implementación del proceso de consulta previa, libre e informada sobre el desarrollo de un proyecto de generación de energía eólica, de conformidad con estándares del convenio 169 de la Organización Internacional del Trabajo sobre pueblos indígenas y tribales en países independientes ${ }^{6}$. Ambos fueron elaborados sin la participación de los pueblos interesados.

No desarrollaré de manera exhaustiva la experiencia y movilización que diversas organizaciones impulsaron en

suspendió la licencia ambiental y ordeno realizar la consulta. Guatemala:(Sentencia de 21 de diciembre de 2009, expediente 3878-2007). “... siendo que el derecho de consulta es uno de los derechos que le asiste a los pueblos indígenas, es claro que el desarrollo de la regulación normativa de tal derecho, sea por vía legislativa o por vía reglamentaria, debe realizarse por el Gobierno del Estado de Guatemala con la participación coordinada, sistemática y armónica, con los integrantes de dichos pueblos, pues no es concebible que el derecho de consulta que persigue concretizar los derechos de los pueblos indígenas, sea regulado sin la amplia participación de los mismos..."( sentencia de 24 de noviembre de 2011, expediente 1072-2011).

${ }^{5}$ Aprobado por el pleno de la asamblea del consejo consultivo de la CDI en la XXXIII sesión ordinaria.febrero de 2013.

${ }^{6}$ Firmado por SENER,SEGOB,SER,SEDATU,CDI, INAH, Gobierno de Oaxaca.Ayuntamiento del municipio de Juchitán de Zaragoza. 
Juchitán para oponerse al referido proyecto.

El proceso tuvo episodios de agresiones violentas a los opositores, inclusive una de ellas Bettina Cruz, de la Asamblea de los Pueblos del Istmo en Defensa de la Tierra y el Territorio (Apidtt) fue sometida a proceso penal del que finalmente resultó absuelta ${ }^{7}$. Anotaré elementos significativos para centrarme en el análisis de la asamblea consultiva y conclusiva.

\section{ANTECEDENTES}

El Instituto de Investigaciones Eléctricas $^{8}$ reconoció el potencial de los vientos en el istmo de Tehuantepec, que tienen velocidades de hasta 20 m/s. En 1994 se construyó en la zona el primer parque eólico La Venta. Posteriormente se impulsó la creación del corredor eólico del istmo de Tehuantepec. La empresa española Preneal, llegó al istmo en México en 2004, asociada con la Comisión Federal de Electricidad, cuyo objetivo es promover, construir y explotar parques eólicos. El 8 de noviembre de 2004, sin consultar a los pueblos y con diversos engaños, Preneal obtuvo el usufructo de mil 643 hectáreas de tierras

\footnotetext{
7 Destacan entre las organizaciones opositoras la Asamblea del Pueblo de San Dionisio del Mar (APSDM); la Asamblea de Pueblos Indígenas del Istmo en Defensa de la Tierra y el Territorio; la Asamblea del Pueblo Juchiteco, la Asamblea Popular del Pueblo Juchiteco, el Comité de Defensa Integral de Derechos Humanos Gobixha , la
}

comunales. En 2011 los comuneros tuvieron acceso al contrato abusivo que les hizo firmar la empresa, y desde entonces comenzaron una lucha en defensa de su territorio, específicamente de la isla, lugar sagrado para su pueblo. Su rechazo al proyecto es también por la grave afectación a su forma de vida y supervivencia de su cultura; además de la afectación total al ecosistema marino, considerado por la Comisión Nacional para el Conocimiento y uso de la Biodiversidad como una región prioritaria por su alta diversidad biológica.

Dentro de las múltiples iniciativas de defensa jurídica de las organizaciones citadas, lograron ,en 2013, la suspensión de plano otorgada por el juzgado séptimo de distrito en el estado de Oaxaca, en respuesta a la demanda de amparo de la comunidad de San Dionisio del Mar contra Mareña Renovables -(MR) sociedad de inversión con capitales de Holanda, Japón, Australia, México y España. En consecuencia la empresa anunció que ya no construiría el parque eólico San Dionisio en la barra de Santa Teresa y reubicaría 270 aerogeneradores en otra parte del istmo de Tehuantepec.

Asamblea Comunitaria de Álvaro Obregón y la Unión de Comunidades Indígenas de la Zona Norte del Istmo.

${ }^{8}$ Creado en 1975 como organismo descentralizado adscrito a la Secretaría de Energía del Estado Méxicano 
A raíz de ello, la empresa modificó su razón social -ahora se llama Eólica del Sur para retomar el proyecto en tierras comunales de barra de Santa Teresa, en el municipio de San Dionisio del Mar, y en la agencia de Álvaro Obregón de Juchitán.

\section{ESTRUCTURA DEL PROTOCOLO DE CONSULTA DE LA SECRETARÍA DE ENERGÍA (SENER)}

Como ya señalamos, dicho Protocolo se elaboró sin participación indígena, con una carga institucional que no dá preeminencia a los titulares del derecho a la consulta:

1. Comité técnico asesor ${ }^{9}$

a) Ayuntamiento Juchitán,

b) Gobierno de Oaxaca,

c) Gobierno federal: energía, semarnat gobernación, relaciones exteriores sedatu, inah,cdi

2. Órgano garante: la subsecretaría de derechos humanos de Gobernación

3. Grupo asesor de academia y organizaciones de la sociedad civil: Programa Universitario de la Diversidad y la Interculturalidad de la UNAM, CIESAS, Fundar, Universidad de Chapingo, ENAH, UAM Xochimilco, Unión de

\footnotetext{
${ }^{9}$ Proviene del protocolo de CDI 2013 pag 36.

${ }^{10}$ Según dictamen "antropológico." elaborado por la Comisión Nacional de Desarrollo de los Pueblos Indígenas CDI
}

Científicos Comprometidos con la Sociedad y otros

4. Observadores

El anterior relator de ONU-Pueblos Indígenas James Anaya e Integrantes del Foro Permanente cuestiones indígenas ONU: Instituto Federal de Acceso a la Información, PNUD, CNDH, Alto Comisionado de la ONU en México. Las organizaciones: proyecto de derechos económicos, sociales y culturales, Código $\mathrm{H}$ comisión de derechos humanos gobicha, Brigadas Internacionales de $\mathrm{Paz}$ y un representante de congreso de Oaxaca.

\section{PROTOCOLO: CAPÍTULO DEL SUJETO COLECTIVO DEL DERECHO A LA CONSULTA PREVIA}

El ayuntamiento de Juchitan elaboró la propuesta. Si bien se definió que es la comunidad indígena de Juchitán de Zaragoza perteneciente al pueblo indígena zapoteco de Oaxaca, municipio y distrito de la Heroica Ciudad de Juchitán de Zaragoza, al precisar las llamadas instancias representativas ${ }^{10}$ se enlistaron una amplia y difusa gama, partiendo $\mathrm{de}^{11}$ :

\section{A. La asamblea, comisariado y consejo de vigilancia y /o integrantes del patrón básico de comuneros y comuneras;}

\footnotetext{
${ }^{11}$ Negritas y subrayados son míos.
} 
B. Poseedores (as) de los terrenos donde se pretende construir el proyecto;

C. Habitantes de localidades y o asentamientos humanos: $\mathrm{El}$ Tamarindo, Huanacastal, la Guadalupana y Rancho La Soledad, Simona Robles y demás localidades afectadas por el desarrollo del proyecto:

D. Las y los representantes de las instituciones educativas y culturales ubicadas en las áreas de influencia del proyecto.

E. Autoridades municipales: Presidente Municipal, síndicos, regidores y (as)

F. Las y los integrantes del Consejo Municipal de Desarrollo Social que forman parte de la cabecera municipal de la H.Ciudad de Juchitán de Zaragoza

G. Las y los integrantes del Consejo Municipal de Desarrollo Rural Sustentable

H. Las y los representantes de las sociedades de Velas que realizan ceremoniales en el área de influencia del proyecto.

I. Las y los representantes de comités comunitarios

J. Las y los representantes de Sociedades de Producción Rural, asociaciones de ganaderos y distritos de riego ubicados en las áreas de influencia del proyecto, debidamente acreditados.

K. Las y los representantes de organizaciones de la sociedad civil con actividad en el municipio de la $\mathrm{H}$ Ciudad de Juchitán de Zaragoza

L. Las y los representantes de organizaciones sociales y económicas en el municipio de la $\mathrm{H}$ Ciudad de Juchitán de Zaragoza que tengan relación con el desarrollo del proyecto eólico

M. Las y los representantes del consejo consultivo de la Comisión para el Desarrollo de los Pueblos Indígenas.

N. Las y los representantes del Consejo Consultivo de Pueblos Indígenas de la Secretaría de Asuntos indígenas del gobierno del estado de Oaxaca

O. Las y los representantes de las cooperativas y asociaciones de pescadores artesanales y concluyen subrayando que las autoridades municipales constituyen una instancia representativa de la comunidad indígena de Juchitán de Zaragoza. Y únicamente para el caso de la consulta previa sobre el proyecto de éolica del Sur al que hace referencia el presente protocolo, fungirán solo como autoridad responsable, a fin de facilitar el consenso del presente instrumento. 
PROTOCOLO: ETAPAS DEL PROCESO DE CONSULTA

De acuerdo a información de la Secretaría de Energía $^{12}$ la consulta comenzó el 20 de octubre de 2014, con la publicación de un desplegado en el cual se invitó a las instancias representativas de la comunidad indígena, definidas por el gobierno, a participar en la primera etapa para dialogar sobre el protocolo que sería utilizado. A partir de entonces se inició la fase informativa, se realizaron 11 asambleas de acuerdos previos y nueve informativas, tanto en español como en zapoteco.

Un taller sobre la manifestación de impacto ambiental (MIA), una exposición sobre los potenciales impactos sociales, $\mathrm{y}$ una asamblea de evaluación de la fase informativa, en la Casa de la Cultura de Juchitán.

En las primeras reuniones comunidad y autoridades definieron la forma en que se realizaría la consulta previa; posteriormente se presentó la información relevante sobre el sector eléctrico, el proyecto eólico propuesto, y los impactos potenciales a la salud, al medio ambiente y al patrimonio arqueológico e histórico de la comunidad. Sumado a esto se llevaron a cabo dos talleres sobre temáticas particulares solicitados por la comunidad en el contexto de la fase informativa: un taller sobre las obligaciones fiscales que adquirirían los titulares de predios donde se pretende instalar el parque, y otro sobre la Manifestación de Impacto Ambiental del proyecto. En cada una de las reuniones organizaciones opositoras hicieron llegar observaciones al Comité Técnico Asesor, con denuncias sobre irregularidades y propuestas que no fueron atendidas. Por ejemplo, desde el inicio la Asamblea Popular del Pueblo Juchiteco, en escrito del 12 de noviembre de 2014 cuestionó que el Protocolo no se sometiera a revisión así como la dinámica de las reuniones, la falta de respeto a la consulta en cada una de las siete secciones del pueblo juchiteco.

\section{EL EX RELATOR JAMES ANAYA}

El 23 febrero de 2015 el ex Relator de la ONU sobre Pueblos Indígenas, James Anaya presentó las observaciones de su visita a México del del 3 al 6 de febrero del mismo año. Destacó que la Comunidad zapoteca está dividida, que no existen autoridades tradicionales como tales, anotó que observó un proceso de negociación paralelo al proceso de consulta que podría deslegitimarla por lo que existía el riesgo de que las asambleas amplias fueran simple coreografia. Señaló que no se garantiza el 
carácter previo de la consulta pertinente solo con traductor, que debe abordarse dentro de los beneficios la eventual participación de la comunidad, que la empresa debe participar en la consulta y observó una actitud de la empresa en ver con inferioridad a los indígenas.

Las organizaciones opositoras al proyecto de Eólica del Sur las difundieron y por ello, el 14 de abril de 2015 el propio Anaya emitió un comunicado: "En ningún momento señalé que el estado mexicano comete violaciones a los derechos humanos de la comunidad zapoteca de Juchitán señalé que es loable la participación y los esfuerzos de los tres órdenes de gobierno en la implementación del convenio 169 de la OIT en un contexto muy complejo y si bien señalé deficiencias mi expectativa es que el Estado tome en cuenta mis recomendaciones. Por último anotó que "se debe entender que los derechos humanos de los pueblos indígenas no se violan por la existencia de deficiencias en una consulta sobre el convenio 169, sobretodo si el Estado está tratando de superar dichas deficiencias" $"$.

13 Un virtual cheque en blanco para el Estado. Después de ello no se ha pronunciado públicamente. ${ }^{14}$ La Información de esta sesión proviene de video de la misma, con duración de cuatro horas, del cual
SESIÓN FINAL DEL PROCESO DE CONSULTA EN JUCHITÁN; 30 DE JULIO DE 2015 14

Fue impresionante el escenario, discurso y actitudes de las y los integrantes de la asamblea en torno a los gritos de "ha llegado el progreso" sin la participación de los opositores salvo dos personas que intentaron disentir y fueron acallados a gritos por el público. Nada que ver con una discusión comunitaria.

La funcionaria de la Secretaria de Energía (SENER) Katia Puga abrió la sesión y abordó los compromisos del gobierno federal mencionando reiteradamente que fueron definidos "responsablemente" a partir de una estrategia de "sustentabilidad energética" y que consistirán en reducción de tarifas del pago por servicio de luz que cobra la Comisión Federal de Electricidad en aproximadamente un 35\%; cambio de luminarias que repercutirá en ahorro para el consumo que el municipio paga mensualmente. De esta manera se puede destinar ese ahorro a obras sociales; y la reparación del sistema de bombeo de agua potable. Destacó la creación de un parque eólico municipal para el cual el gobierno federal aportará un aerogenerador de 2 mega wats y el gobierno del estado de

se transcribieron elementos a destacar y se localiza en You Tube, pues la versión estenográfica que anunció la SENER no aparece en su página web. 
Oaxaca aportará un aerogenerador de 3 megawats. Con ello se generaría un ahorro del $35 \%$ del gasto en pago de luz. En el momento en que quede instalado el parque, tardaría varios años, el gobierno federal dejaría de pagar el subsidio de $35 \%$. También señaló la funcionaria que se busca que la población alcance beneficios tangibles con otra tecnología, para lo cual se crearía un centro de energías alternas en el municipio de Juchitán. El local para ese centro lo aportaría la Secretaría de Gobernación. El representante del Gobierno del Estado de Oaxaca, ratificó el compromiso del aerogenerador de 3 megawats para 2016 y anunció obras públicas como un centro de convenciones entre otras que se iniciarían en 2015 con recursos del programa denominado Fonregión. El director de la Empresa Eólica del Sur inició diciendo "gracias por acompañarnos”. Y abordó los beneficios directos que consistirán en pagos a la comunidad que promueven el desarrollo a través de pagos a los titulares de los terrenos, empleos temporales que serán de 150 hasta 350 en la fase de construcción que durará de 15 a 18 meses, y en fase de operación de 40 a 55 empleos.

Dentro de los beneficios indirectos señaló el riego a través de ubicación de zonas hidraúlicas, el compromiso de preservar el medio ambiente, la flora, la fauna, (señaló que no se pierde la flora, pues se reutiliza y reacomoda en otra parte $i$ ?), la mejora de caminos internos y el respeto al libre tránsito. También crearán un fideicomiso de energía eléctrica con un fondo de 4.5. millones de pesos anuales.

$$
\text { Enseguida se realizaron }
$$
intervenciones de los participantes durante cerca de tres horas, todo ellos repetían las mismas frases "queremos empleo, "ya basta de retrasar la decisión" queremos el parque eólico" es histórico" digamos sí, alguno señaló yo vendí porque eran mis tierras, queremos el progreso. Arriba el progreso, está llegando el momento del cambio. Como anoté arriba, solo dos personas intentaron aportar una visión crítica y el público les gritaba, les abucheaba con trabajos lograron señalar que les estaban manipulando, que no se hablaba de los daños que se ocasionaría, que se aprovechaban del atraso económico de la población. La integrante del Grupo de Mujeres 8 de marzo inició con si a la eólica pero ignoraron a las mujeres en los beneficios que ofrecen.

Llamó la atención que se cumplió con el protocolo de la traducción en lengua indígena solo que media hora de intervenciónes se traducía en 4 minutos. En general el auditorio no prestaba atención fuera de aplaudir y gritar "si a la eólica si a la eólica". 
CIERRE DE LA SESIÓN: TRANSMUTACIÓN DE CONSULTA A CONSENTIMIENTO

La parte final de la sesión fue dirigida por el Presidente Municipal de Juchitán, Saul Vicente, conocedor de los andares de la ONU, representante de México ante el Foro Permanente de Cuestiones Indígenas de la ONU y militante partidista de la izquierda en México. Esta experiencia se refleja en el cuidado- por cierto aparente- de las formas. Cada una de las decisiones que le interesaban fueron sometidas a votación a mano alzada, dando lugar a la evidencia de casi ausencia de votos en contra o abstenciones para concluir con un voto a su favor, del presidente Municipal como representante de todo el pueblo.

En primer lugar aclaró que los 1500 asistentes eran representantes cuya presencia había sido precedida de reuniones y de la entrega de firmas- por supuesto a favor del parque eólico. Cuestionó sin mencionarlas a organizaciones ausentes como la de Bettina Cruz que ha tramitado amparos y señaló posiblemente intentarán cuestionar ante jueces pero "no importa la decisión que se tome porque aquí el juez

15 La mesa estaba integrada por dependencias gubernamentales, la empresa y los sindicos del ayuntamiento que él preside. somos nosotros y aclaró- ustedes, son ustedes, hicieron sus asambleas los 1500 son representantes, cada uno entregó firmas y otras 15 organizaciones con otras $7 \mathrm{mil}$ firmas y su acta. Todo es un esfuerzo. A lo mejor me puedo equivocar al permitir que vengan empresas y no traigan ningún beneficio. En esta asamblea retoman el acuerdo de la asamblea anterior que pidieron que en esta se trajeron los beneficios

Hoy se expusieron claramente y todas y todos dijeron Si están de acuerdo para que sea válida me voy a permitir en nombre de la mesa ${ }^{15}$ que levanten la mano

1. Si están de acuerdo en las propuestas y beneficios. SIIII unánime, nadie en contra, sin abstención. Resultado, para el acta: se aceptan las propuestas y beneficios.'

2. Hermanos, hermanas ¿se da o no el consentimiento para la instauración del Parque Eólico del Sur? Abrumadora aprobación, una abstención, ninguna en contra. Resultado para el acta: Con esto se toma la decisión de otorgar el consentimiento.

Cerramos esta decisión histórica y también les pregunto; 
3. Me están pidiendo que haga una firma a nombre de todas las instancias. Están de acuerdo en que Saúl Vicente Vásquez firme en su nombre? A favor casi todos, uno en contra, una abstención. Con este acuerdo se anexan todas las firmas de los presentes.

Paisanos y paisanas: Cerramos esta decisión, recoge lo que esperaba la mayoría, es un primer paso histórico en la toma de decisiones, eso es lo importante y así se hará con otras empresas porque no existe ley en el país ni en el mundo que señale los pasos, esto es un ejemplo para todo el país. Quedan formalmente aprobados los acuerdos el 30 de julio de $2015^{16}$.

En consecuencia, la SENER en un boletín de prensa ${ }^{17}$ señaló que con la aprobación de la comunidad, concluye el proceso de consulta previa, "libre e informada", que durante ocho meses realizó junto con los gobiernos estatal y municipal, así como con más de 10 dependencias de los tres órdenes de gobierno integrantes del comité técnico asesor.

La dependencia insistió en que el proyecto cuenta con el consentimiento "libre e informado de la comunidad indígena zapoteca de El Espinal, otorgado también luego de una consulta, por lo cual

\footnotetext{
${ }^{16}$ La Sener mediante boletín 071 del 4 de agosto de 2015 dio cuenta de la conclusión del proceso y de sus resultados.
}

la construcción del nuevo proyecto se iniciará en breve.

El parque consiste en 132 aerogeneradores para lograr una capacidad total de $3 \%$ megavatios y una producción estimada en ínil310GWh. Tendrá un costo estimado de 14 mil 454 millones de pesos, lo cual representa una de las inversiones de la industria eólica en el estado "más importantes en los últimos años".

Ésta es la primera ocasión que la autoridad desarrolla una consulta de carácter indígena con fundamento en la legislación nacional, la Ley de la Industria Eléctrica (capítulo II, artículos del 117 al 120), modificada a partir de la Reforma Energética. La consulta de Juchitán, será el referente a seguir para los proyectos derivados de ésta reforma. Los procedimientos de consulta previa a las dos comunidades indígenas, que podían ser afectadas en sus derechos e intereses colectivos, fueron realizados por la SENER de conformidad con el Convenio 169 de la Organización Internacional del Trabajo (OIT), el artículo primero de la Constitución Política de los Estados Unidos Mexicanos y el artículo 119 de la la Ley de la Industria Eléctrica, aseguró la dependencia.

\footnotetext{
174 de agosto de 2015, número 071
} 
Detalló que en la última fase de la consulta participaron "más de mil 300 representantes de la comunidad indígena, quienes manifestaron su acuerdo con los beneficios asociados al proyecto $\mathrm{y}$ otorgaron su consentimiento libre e informado". Y sintetizó que entre los supuestos beneficios destaca la puesta en marcha de una estrategia de sustentabilidad energética en apoyo de la comunidad que promueva el uso de energías limpias y la eficiencia energética, mediante proyectos de corto, mediano y largo plazos.

De igual forma, compromisos $\mathrm{y}$ obligaciones adquiridos por la empresa, como "el cumplimiento de sus obligaciones fiscales, de todas las medidas de mitigación que salvaguarden el medio ambiente y los recursos naturales; la creación de un fideicomiso que destinará recursos para la reducción de la factura eléctrica doméstica de los usuarios de la tarifa $1 \mathrm{C}$, habitantes del municipio de Juchitán de Zaragoza".

El gobierno federal destinará fondos para un proyecto de eficiencia energética en los servicios municipales y para la adquisición de un aerogenerador con tecnología mexicana operado por el Instituto de Investigaciones Eléctricas, que destine la energía generada al consumo de los usuarios residenciales de la tarifa $1 \mathrm{C} \mathrm{del}$ municipio, mientras el gobierno estatal adquirirá un segundo aerogenerador, con el propósito de determinar las bases de un parque eólico municipal que pudiera crecer en el largo plazo en beneficio de la comunidad.

\section{OPOSICIÓN CON LA LEY EN LA MANO:}

Ante el anuncio de la Secretaría de Energía (SENER) de que se iniciará la construcción del parque eólico de la empresa Eólica del Sur en las comunidades de Juchitán y de El Espinal, en el Istmo de Tehuantepec, Oaxaca. El 15 de Septiembre de 2015, 1166 indígenas de la comunidad binni'zaa del Istmo de Tehuantepec interpusieron un amparo que recayó en el Séptimo Juez de Distrito de Salina Cruz, con el fin de proteger sus derechos al considerar que fueron violados por las autoridades federales, estatales $y$ municipales al aprobar la construcción y operación del megaproyecto de Energía Eólica del Sur en su territorio indígena. El 30 de Septiembre el Juez dictó una orden de suspensión de todas las autorizaciones, permisos, vistos buenos, aprobaciones, licencias y cambios del uso de suelo otorgados. El 11 de diciembre de 2015 el Juez Séptimo de Distrito en el Estado de Oaxaca otorgó la suspensión definitiva . Sin embargo el 9 de junio de 2016, un nuevo Juez Séptimo de Distrito en Salina Cruz Oaxaca, en audiencia constitucional 
resolvió sobreseer y negar el amparo a la comunidad, señalando que el proyecto Eólica del Sur sí fue consultado de forma previa y en apego a los parámetros internacionales. Este veredicto dejó en indefensión al pueblo zapoteco y el Tribunal Colegiado de Oaxaca al resolver el recurso de revisión, levantó la suspensión del proyecto. Sin embargo en los hechos el proyecto continúa suspendido ${ }^{18}$. Los opositores no se confían, solicitaron que la Suprema Corte de Justicia de la Nación (SCJN) atrajera el caso y el 10 de enero de 2018, la Primera Sala de esta máxima instancia del Poder Judicial lo acordó por unanimidad indicando que el asunto reúne los requisitos de interés y trascendencia, en tanto que involucra el contenido y alcance del derecho humano a la consulta previa, libre e informada de las comunidades indígenas ${ }^{19}$.Es deseable que la decisión que en su momento tome SCJN en la revisión de este caso, avance en criterios que fortalezcan este derecho.

\section{UN PROBLEMA INSOSLAYABLE: LA REPRESENTATIVIDAD}

\footnotetext{
${ }^{18}$ El embajador de Derechos Humanos de los Países Bajos, Kees van Baar, en visita a México recordó que en abril de 2016, el fondo de manejo de pensiones, de origen holandés, retiró una inversión de 250 millones de euros para un proyecto eólico en
}

Si bien está en curso la defensa jurídico ambiental del "consentimiento" logrado por la SENER, el caso que hemos presentado nos plantea la necesidad de abordar el tema de la representatividad, no solo como se mostró en el Protocolo de consulta de Juchitán que definió una amplia gama de las llamadas instancias representativas que no forman parte de las instituciones propias, sino también porque es real en ese caso y en muchos otros pueblos las transformaciones que han sufrido en la relación histórica de exclusión han motivado que desaparezcan sus formas propias y o se mimeticen o subsuman en instancias de organización política como los municipios por ejemplo en el estado de Oaxaca de manera destacada (Speiser:2013). Y aún en ese caso conservan la asamblea comunal. También se presenta la superposición con las formas de tenencia de la tierra que son afectadas con los proyectos. Todo ello tiene el trasfondo de que no se incorpora el derecho al territorio mucho menos el de autonomía y libre determinación como elementos inherentes a los pueblos indígenas. Por lo demás influyen las prácticas políticas del Estado mexicano, que ciertamente le son tradicionales, como el clientelismo de los

el Istmo de Tehuantepec debido a la oposición de las comunidades. Periódico Reforma, 13 de febrero de 2017.

${ }^{19}$ Comunicado 003, 10 de enero de 2018.SCJN. 
programas gubernamentales, la cooptación por esa y otras vías que se traducen en divisionismo y desintegración de las formas propias de organización social de los pueblos indígenas. En muchos casos los derechos les han llegado tarde, por ello algunos se han planteado alcanzar la reconstitución de sus pueblos, tarea compleja sin duda.

\section{CRITERIOS DE LA OIT SOBRE REPRESENTATIVIDAD}

En el documento de la OIT relativo a las reclamaciones promovidas de parte indígena desde México por violación al derecho de consulta, en el diseño y aprobación de la reforma constitucional relativa a pueblos indígenas de 2001, se incorporó el tema de la representatividad ${ }^{20}$ en estos términos: El artículo 6.1, a) del Convenio, al consagrar la obligación a cargo de los gobiernos de consultar a los pueblos interesados, establece que deberán hacerlo «en particular a través de sus instituciones representativas».

"Según el Gobierno, el poder legislativo federal consideró que las organizaciones más representativas del movimiento indígena, eran el Congreso Nacional Indígena (CNI) y el Ejército

\footnotetext{
${ }^{20}$ GB289/17/3/2004-02-0047-3ES Doc parágrafos
} 69,97 a 103.
Zapatista de Liberación Nacional ( EZLN ${ }^{21}$ seguidas por académicos y personalidades dedicadas a problemas indígenas. Manifiesta que el Gobierno buscó todos los medios de consulta con quienes, en afirmación del Sindicato del Instituto Nacional de Antropología e Historia que promovió la reclamación ante OIT, constituyen los representantes del movimiento indígena nacional, tanto por criterios numéricos, como de corriente de opinión y apegados siempre a criterios objetivos contenidos en la Ley de Planeación y el Plan Nacional de Desarrollo. Agrega que el dictamen fue el resultado de un profundo trabajo legislativo y gubernamental en el que intervinieron no sólo los diputados y partidos políticos sino también dependencias gubernamentales, gobiernos estatales y grupos indígenas de distintos puntos del país". Y la OIT señaló que: "El Comité no pone en duda la buena fe del Gobierno al consultar con el EZLN, lo cual adquiere mayor sentido aún en las circunstancias en que se produjo, puesto que esa consulta se dio en el marco de un conflicto entre el EZLN y el Gobierno. Esto se ajusta a lo establecido en el artículo 34 del Convenio según el cual: La naturaleza y el alcance de las medidas que se adopten para dar efecto al presente Convenio deberán determinarse con flexibilidad,

\footnotetext{
${ }^{21} \mathrm{CNI}$;Congreso Nacional Indígena, EZLN; Ejército Zapatista de Liberación Nacional.
} 
teniendo en cuenta las condiciones propias de cada país. Esto no implica poner en duda la representatividad de dichas organizaciones, cuestión que el Comité no examinó. El Comité observa que el Gobierno se refiere al EZLN y al CNI como a las «organizaciones más representativas del movimiento indígena» en tanto que el Convenio se refiere a las «instituciones representativas de los pueblos indígenas». Y continuó indicando que "Dada la diversidad de los pueblos indígenas, el Convenio no impone un modelo de institución representativa, lo importante es que estas sean el fruto de un proceso propio, interno de los pueblos indígenas. Pero es fundamental cerciorarse de que la consulta se lleva a cabo con las instituciones realmente representativas de los pueblos interesados. Como ya lo estableciera el Consejo de Administración en otra oportunidad, «... el principio de representatividad es un componente esencial de la obligación de consulta. (...) pudiera ser difícil en muchas circunstancias determinar quién representa una comunidad en particular. Sin embargo, si no se desarrolla un proceso de consulta adecuado con las instituciones $\mathrm{u}$ organizaciones indígenas y tribales verdaderamente

\footnotetext{
${ }^{22}$ Basado en el Informe del Proyecto 123396 "El impacto social del uso del recurso eólico" del Centro de Investigación y Antropología Social. CIESAS con apoyo de Conacyt.
}

representativas de las comunidades afectadas, la consulta encaminada no cumpliría con los requisitos del Convenio». Quedó así planteada la distinción entre organizaciones del movimiento indígena e instituciones representativas de los pueblos indígenas.

\section{¿EN JUCHITÁN EL ESTADO DIVIDIÓ AL PUEBLO ZAPOTECO O APROVECHÓ LA CRISIS COMUNITARIA INDÍGENA PREVIA?}

Mientras transcurría la consulta en Juchitán se dio a conocer el libro La visión de los actores sociales frente a los proyectos eólicos del Istmo de Tehuantepec cuyo coordinador general es el destacado antropólogo Salomon Nahmad Sitton ${ }^{22}$ (Nahmad:2015). La SENER lo consideró propicio a sus intereses e incorporó a los foros de consulta la difusión de su presentación en el texto de la convocatoria al taller sobre la Manifestación de Impacto Ambiental, aduciendo que el Ciesas formó parte del comité asesor ${ }^{23}$. El estudio se basó en la realización de entrevistas ${ }^{24}$ a ejidatarios en las comunidades de parques eólicos ya instalados: La Venta y La Ventosa del municipio Juchitán, La Mata municipio Asunción Ixtaltepec o pequeños

\footnotetext{
${ }^{23}$ Convocatoria al taller para el 23 de marzo de 2015 y al libro el 24 de marzo de 2015.

${ }^{24}$ Además de fuentes documentales.
} 
propietarios como el Espinal municipio del mismo nombre.

Algunas de sus afirmaciones:

a) En sentido social uno de los riesgos es la atomización de las comunidades por la presencia de agentes diversos encargados de convencer a los campesinos de ceder sus tierras a empresas que se han repartido comercialmente el territorio, especulando con el suelo. Divide a los opositores en los genuinos por desconocimiento y los que manejan un discurso político que requiere muchos recursos económicos para sus viajes a foros internacionales $\mathrm{o}$ en otras ciudades del país, videos, películas impresión de folletos que alegan violación de derechos y expresan preocupación por el medio ambiente "catastrofistas" la mayoría no son directamente afectados por los proyectos o no tienen tierras. Discurso de opositores "cada vez más desgastado y falto de argumentos sólidos". Las comunidades que ya tienen parques eólicos no coinciden con ese tipo de preocupaciones.

b) Las comunidades divididas entre arrendatarios y no arrendatarios. Los primeros tienen voz interesada.

c) Señala que en torno al Rol de la autoridad ejidal se tejen historias relativas a corrupción y que hay de todo son los encargados de mediar en la renta de tierra, su rol es superior a los presidentes municipales.

d) Las empresas tienen más interés en las tierras que en los que habitan en ellas: Ofrecen pocos empleos de baja remuneración y en mantenimiento o vigilancia; la pavimentación de calles o el remozamiento de escuelas. Algunos piensan que con la construcción de vías para los aerogeneradores se destruyeron las vías naturales de desague y ello ha provocado inundaciones; poco impacto de los que reciben rentas para la manutención y alguno ha puesto un negocio

e) Recomienda que el gobierno vigile el cumplimiento de las empresas con los beneficios comunitarios que resultan insignificantes, asesoría gubernamental a los arrendadores de tierras; que se hagan estudios de impacto social

El estudio omite toda consideración a las autoridades representativas indígenas, se ubica con la tenencia de la tierra, no refiere a la consulta como derecho, al impacto ambiental y al descalificar a los opositores y recomendar mejores negociaciones en los contratos implícitamente avala los proyectos eólicos. Como vemos hubo razones fundadas para el interés de la SENER en difundirlo. La disputa por la representatividad está presente, lo que fue aprovechado para levantar simples listas de firmas en la sesión final ya comentada. Todo un escenario propicio para que el 
Estado mexicano patente su protocolo de consulta.

\section{PERSPECTIVA}

A raíz de los movimientos de resistencia indígena en América latina y la utilización del derecho a la consulta para enfrentar megaproyectos y concesiones mineras, las empresas han recurrido a su espacio natural "gremial" como es la Organización Internacional de Empleadores (OIE), integrante de la tripartita Organización Internacional del Trabajo (OIT) desde 1920. Está centrando baterías en el campo indígena como parte del creciente activismo de empresas sobre todo trasnacionales implicadas y según ellas afectadas por el rechazo indígena a su accionar en perjuicio de los pueblos. En este sentido encontramos una evidencia dentro del Informe de la comisión de expertos en aplicación de convenios y recomendaciones, presentado en la Conferencia Internacional del Trabajo (102 reunión, 2013), en el cual se incluye la Comunicación que presentó la OIE en agosto de 2012 destinada a la OIT, pero con evidente dedicatoria a los diversos Estados que han ratificado el Convenio 169. Ese año se dirigieron observaciones en el informe respecto a Argentina, Bolivia, Brasil, Chile, Colombia Guatemala, Honduras, Paraguay,
Perú y la República Bolivariana de Venezuela.

En cada uno de estos países se incluyó, con texto similar, la comunicación referida en la cual se anotan como problemas la identificación de las instituciones representativas, la definición de territorio indígena y la falta de consenso entre los pueblos indígenas y tribales sobre sus procesos internos, y la importancia de que la Comisión de Expertos sea consciente de las consecuencias que estos asuntos tienen para la seguridad jurídica, el costo financiero y la previsibilidad de las inversiones tanto públicas como privadas.

La OIE se refiere a las dificultades, los costos y el impacto negativo que el incumplimiento por parte de los estados de la obligación de consulta puede tener en los proyectos que llevan a cabo empresas tanto públicas como privadas y observa que la mala aplicación e interpretación del requisito de consulta previa puede implicar obstáculos legales y acarrear dificultades para los negocios, afectar a la reputación y tener costos financieros para las empresas, entre otras cosas. También declara que las dificultades para cumplir con la obligación de consulta pueden tener repercusiones sobre los proyectos que las empresas quieren llevar a cabo a fin de crear un entorno propicio para el desarrollo económico y social, la creación de trabajo 
productivo y decente y el desarrollo sostenible del conjunto de la sociedad. Esta postura tiene como telón de fondo el fracaso empresarial en sus iniciativas orientadas a dividir a los pueblos a través de ofertas económicas destinadas a construir supuestos consensos contra las organizaciones que están resistiendo a estas empresas con la complicidad activa en algunos casos de los estados o bien con la omisión de los mismos frente a su deber de consultar a los pueblos.(Aywiln:2014).

Ya desde 2011 la OIT había presentado una observación general justificada en las crecientes quejas de los empleadores (empresas) y conflictos, donde aclaró que la consulta no es equivalente al derecho a veto para lo cual señaló que tal criterio fue rechazado por los estados desde que se discutió el texto del Convenio 169. En esta ocasión se optó por invitar al gobierno respectivo a incluir en su próxima memoria los comentarios que juzgue oportuno al respecto de las observaciones de la OIE..En México encontramos posturas similares a las de la OIE, donde las empresas se justifican y el Estado da respuestas triviales. En el informe presentado en la sesión 2013 del Foro Permanente sobre Cuestiones Indígenas de la ONU (E/C.19/2013/11) se consigna la postura de la Cámara Minera de México (Camimex) que reivindica buenas prácticas, las cuales, según sostienen, constituyen uno de los sectores más dinámicos de la industria mexicana y aporta mayores beneficios a la balanza comercial de México, ofrece a los trabajadores los mejores salarios y realiza sus operaciones de manera sostenible, respetando el ambiente y los códigos de conducta establecidos a escala internacional para este tipo de empresas. Asimismo,el gobierno mexicano en la memoria a la OIT de septiembre de 2013 incluyó comunicación de la confederación de cámaras industriales de los estados unidos mexicanos (concamin),donde señala que es importante definir y poner en practica programas en beneficio de los diversos grupos indigenas $\mathrm{y}$ tribales y también manifiesta su preocupación por la confusión que podría generar el hecho de tener que someter toda acción en materia de infraestructura o de desarrollo económico o social a la aprobación de los pueblos indígenas.

La reforma energética está avanzando y el derecho de los pueblos al territorio, ha quedado en los hechos restringido y subordinado a una supuesta consulta, la cual como señalamos afecta a las empresas. En esos márgenes están desarrollando su defensa jurídica, con algunos triunfos que consisten en ordenar la consulta sin que se ordene la suspensión de los proyectos impugnados. Hoy la noción 
de interés público favorece al capital transnacional. Aún así la resistencia indígena opera en diversas regiones del país. Por ello no es casual que los líderes sean criminalizados: Contra el Acueducto Independencia, en Sonora, el yaqui Mario Luna.En el caso de los yaquis, el agravio se potencia, pues han logrado diversos triunfos jurídicos en tribunales que no se han respetado $^{25}$ (Gómez:2014); contra la presa La Parota, en Guerrero, Marco Antonio Suástegui ${ }^{26}$; por las policías comunitarias en Guerrero y Michoacán, Nestora Salgado y Cemeí Verdía Zepeda. A todos les han fabricado acusaciones para convertirlos en ladrones o secuestradores. Y anotamos sólo unos ejemplos, porque hay por lo menos un centenar de conflictos en curso de este rango y están promoviendo recursos jurídicos para su defensa, con la paradoja de que al obtener eventualmente fallos en su favor, éstos no se cumplen. Constituyen en cambio un eslabón para el despojo que impide la expresión del derecho indígena en lógica autonómica y emancipatoria.(Santos:2002).

25 La tribu yaqui que impugnó el Acueducto Independencia y logró que la Suprema Corte reconociera que la manifestación de impacto ambiental en favor de dicho proyecto debería reponerse incorporando el derecho a la consulta y, tras un proceso caótico, la consulta está suspendida, inmersa en una serie de irregularidades de las que ha dado cuenta la misión civil de observación en su segundo informe denominado sentencia fallida. Hoy el acueducto funciona, y uno de los más activos
Por todo ello, advertimos que en este texto,solo mostramos la punta del iceberg de una problemática más amplia, que incluye las escasas condiciones de acceso a la justicia para los pueblos indígenas; el impacto del despojo territorial que han sufrido; el riesgo presente con megaproyectos, concesiones mineras y aún las exploraciones en materia energética y, en general, su situación de exclusión sistemática, así como el racismo y la discriminación que prevalece en nuestra sociedad. Muy lejos estamos de la propuesta emancipatoria.

\section{Referencias}

\section{AYWILN JOSE Y LEONARDO}

TAMBURINI editores. Convenio

169 , los desafíos de su

implementación en al a 25 años de su aprobación IWGIA Santiago, Chile 2014.

CIDH. Derechos de los pueblos indígenas y tribales sobre sus tierras

opositores yaquis, Mario Luna, fue encarcelado con un proceso plagado de violaciones y absurdos, pues se dijo en el auto de formal prisión que no le aplica el artículo segundo constitucional porque no es autoridad tradicional y se le acusó de delitos sin evidencia de su participación, desechando las pruebas de la tribu. Fue liberado en septiembre de 2015.

${ }^{26}$ Liberado en 2015,tras dos años en prisión. 
ancestrales y recursos naturales.

Normas y jurisprudencia del Sistema

Interamericano de Derechos

Humanos 2010

COSSIO José Ramon Las Trampas

del consenso, Revista Nexos $1^{\circ}$ de

octubre. México 2013 p.p.22-24

FERRER MC GREGOR Eduardo,

CABALLERO José Luis, STEINER

Christian. Derechos Humanos en la

Constitución: comentarios de

jurisprudencia constitucional e

interamericana. Tomo I SCJN-

UNAM-IIJ y fundación Konrad

Adenauer.2013.

GOMEZ, Magdalena, "La Constitucionalidad

Pendiente: la hora indígena de la

Corte", en: El Estado y los Indígenas en tiempos del PAN,

neoindigenismo, legalidad e identidad Porrúa, CIESAS, Cámara de Diputados, México, 2004. .

"Pending Constitutionality:

An Analysis of the Mexican Legal

Reform Process Concerning

Indigenous Peoples", en: Rene

Kuppe y Richard Potz (Eds.), Law

and Anthropology. International

Yearbook for Legal Anthropology,
Martinus Nijhoff Publishers, Leiden-

Boston, vol. 12, pp. 175-195.2005.

"El Convenio 169 de la

Organización Internacional del

Trabajo", en: Mikel Berraondo

(Coord.), Pueblos indígenas y

derechos humanos, Bilbao,

Universidad de Deusto, pp. 133-

151.2006.

Justicia y diversidad en

América Latina. Coordinado por

Teresa Sierra, Victoria Chenaut

,Magdalena Gómez y Héctor Ortiz.

CIESAS México y FLACSO

Ecuador.2011

"Los pueblos indígenas y la

razón de estado en México", en:

Revista Nueva Antropología, UAMCONACULTA-INAH vol XXVI

num. 78, enero junio 2013 p.p. 43-62. 2013.

"Los derechos permitidos a

una década de la contrarreforma

indígena mexicana: problemario", en:

Movimiento indígena en América

Latina: Resistencia y transformación social, vol III. Fabiola Escárzaga, Raquel Gutiérrez, Juan José Carrillo, Eva Capece, Börries Nehe (coords.) México, UAM, BUAP, CIESAS. páginas 637-666 México 2014. 
"Claroscuros del derecho a la

consulta: casos yaqui y del concejo

mayor de Cherán”. En: Nuevas

violencias en América Latina. Los

derechos indígenas ante las políticas

neoestractivistas y las polícitcas de

seguridad, Laura Valladares (coord),

UAM Iztapalapa, Juan Pablos editor,

México. p.p. 185-223. 2014.

"Desviación de poder".

Tribunal Permanente de los Pueblos

capítulo México en: El Otro

Derecho, ILSA, Bogotá Colombia

2015.

OIT

2009.a) Aplicación del Convenio 169

de la OIT por Tribunales Nacionales

e Internacionales en América Latina -

Una Recopilación de Casos - mayo

2009

2009.b)Los Derechos de los Pueblos

Indígenas y Tribales en la Práctica -

Una Guía sobre el Convenio No. 169

de la OIT

\section{NAHMAD SITTON SALOMON}

(coord), La visión de los actores

sociales frente a los proyectos eólicos

del Istmo de Tehuantepec, Ciesas,

México, 2015.
SANTOS BOAVENTURA DE

SOUZA 2002, La globalización del derecho. Los nuevos caminos de la regulación y la emancipación, Colombia, Universidad Nacional de Colombia-Instituto Latinoamericano de Servicios Legales

Alternativos.Bogotá, Colombia.2002

SPEISER SABINE (edit.) Quien

habla por quien? Legitimidad y representatividad de organizaciones y representantes indígenas: un debate abierto. Cooperación Alemana, Quito Ecuador. 2013 